\title{
Analysis of soluble urokinase plasminogen activator receptor in multiple myeloma for predicting prognosis
}

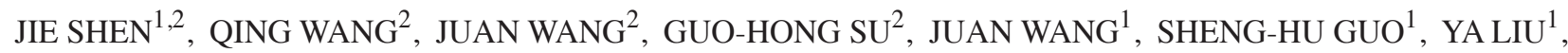 \\ ZHENG WU ${ }^{1}$, RONG-FENG LIU ${ }^{3}$, XING LI $^{1}$, XIAO-JIN GUO ${ }^{1}$, \\ JING CAO $^{1}$, YUE-HUA ZHANG ${ }^{1}$ and ZHI-YU WANG ${ }^{1}$
}

\begin{abstract}
${ }^{1}$ Department of Immunology and Immunotherapy, Fourth Hospital of Hebei Medical University, Shijiazhuang, Hebei 050011; ${ }^{2}$ Department of Hematology, Centre Hospital of Cangzhou, Cangzhou, Hebei 061001;

${ }^{3}$ Department of Oncology, Fourth Hospital of Hebei Medical University, Shijiazhuang, Hebei 050011, P.R. China
\end{abstract}

Received September 7, 2014; Accepted May 29, 2015

DOI: $10.3892 / 01.2015 .3613$

\begin{abstract}
Multiple myeloma is a type of malignancy, which affects the plasma cells of the bone marrow. Recent studies have found that malignant plasma cells may express urokinase plasminogen activator (UPA) and UPA receptor (UPAR), and that initiation of proteolytic events by this system contributes to the process of invasion and destruction of the bone marrow. Studies have also suggested that the level of the soluble form of uPAR (suPAR) may act as a marker for prognosis in patients with multiple myeloma, and that there is an association between uPAR/suPAR expression, and clinical characteristics, efficacy of treatment in disease control and patient survival. In order to investigate this, the present study used flow cytometry to detect the monoclonal antibodies associated with multiple myeloma, specifically, uPAR (CD87), CD56 and CD38. Patients with multiple myeloma were divided into the following groups: The effective groups (remission and stable disease) and the ineffective group (progressive disease). suPAR expression in the effective groups was $257.6 \pm 32.47 \mathrm{pg} / \mathrm{ml}$ and $331.0 \pm 99.80 \mathrm{pg} / \mathrm{ml}$ respectively, which was not significantly different from that of the normal control group $(\mathrm{P}>0.05)$. By contrast, the suPAR level in the invalid group was $562.2 \pm 291.0 \mathrm{pg} / \mathrm{ml}$, which was significantly different from the levels in the normal control group $(\mathrm{P}<0.01)$ and the effective groups $(\mathrm{P}<0.05)$. suPAR levels were positively correlated with disease stage $(\mathrm{P}<0.01)$, renal function $(\mathrm{P}<0.05)$, C-reactive protein $(\mathrm{P}<0.005), \beta 2$-microglobulin $(\mathrm{P}<0.001)$, extramedullary involvement $(\mathrm{P}<0.001)$, chromosome 13 deletion $(\mathrm{P}<0.01)$ and survival $>2$ years $(\mathrm{P}<0.01)$. They were was negatively
\end{abstract}

Correspondence to: Professor Zhi-Yu Wang, Department of Immunology and Immunotherapy, Fourth Hospital of Hebei Medical University, 12 Jiankang Road, Shijiazhuang, Hebei 050011, P.R. China

E-mail: drwangzhiyu@hotmail.com

Key words: soluble urokinase plasminogen activator receptor, multiple myeloma, prognosis, plasminogen correlated with hemoglobin concentration. No correlation was observed between uPAR expression and suPAR levels. The present study also indicated that the stage of disease and suPAR expression were independent factors, which predicted survival of $<2$ years. In conclusion, high suPAR expression appears to predict disease progression, a shortened survival period and early extramedullary infiltration.

\section{Introduction}

Multiple myeloma (MM), also termed myeloma, is a plasmocyte cancer, which may be categorized as a B lymphocytic lymphoma, as plasmocytes represent the final stage of B lymphocyte development. Tumor cells originate from bone marrow plasmocytes. Myeloma usually develops in multiple locations within the bone marrow, which is why it is termed MM. Tumor development is predominantly confined to the bone marrow and may not cause any symptoms during the early stages of disease. However, extramedullary spread may occur at a later stage (1). MM affects the plasma cells within the bone marrow, which are an important component of the immune system. Osteolytic bone lesions in MM may also affect the overall prognosis of patients, due to an increase in bone resorption and a decrease in bone formation.

Urokinase plasminogen activator receptor (uPAR; also known as CD87) is a specific serine protease that connects to the cell membrane with saccharification phosphatidylinositol, which is able to convert plasminogen to its active form, plasmin (1). uPAR is a glycosyl-phosphatidylinositol (GPI)-anchored plasma membrane receptor (2). The uPA system comprises uPA; its receptor, uPAR; substrate molecules, such as plasminogen; and the inhibitory factors, plasminogen activator inhibitor types 1 and 2. It is the major enzyme system involved in degradation of the extracellular matrix and in cell-mediated transfer in the body, under physiological or pathological conditions (3). Furthermore, uPA is involved in tissue remodeling, cell migration and tumor metastasis. Hydrolyzation of the extracellular matrix is an important step in the process of tumor invasion and metastasis, and requires the involvement of a series of proteases (4). In addition to direct degradation of extracellular matrix components, plasmin also catalyses metalloproteinases involved in 
extracellular proteolysis, and uPA, which is secreted by tumor cells, is the activator of plasminogen. The UPAR and its ligand, uPA, constitute the proteolytic system, which is involved in leukocyte infiltration and tissue reconstruction.

In the circulation of cancer patients, uPAR is commonly present in a soluble form (suPAR), which may be detected in bodily fluids and tumor cell extract, and is released by uPAR-positive tumor cells (5). uPA and uPAR are predominantly expressed in blood cells, including neutrophils, monocytes, macrophages and activated T cells, and are hypothesized to be important for the ability of these cells to degrade fibrin, and to extravasate and migrate during an inflammatory response (6). A recent study demonstrated that malignant plasma cells may express UPA and UPAR, and the initiation of proteolytic events by this system may contribute to the process of invasion and destruction of the bone marrow by myeloma cells (3). This type of interaction is an important biological process, which may affect the degradation of marrow, stromal infiltration of plasma cells and the patient's clinical condition.

The present study aimed to measure the level of UPAR and its soluble form (suPAR) in patients with MM, and to analyze the association between UPAR/suPAR and clinical characteristics, treatment effect and patient survival time.

\section{Patients and methods}

Ethics statement. This study was conducted according to the principles expressed in the Declaration of Helsinki and has been approved by the Ethics Committee of Hebei Medical University (Shijiazhuang, China). Participants provided written informed consent to participate in this study.

Clinical materials and grouping. Forty patients with MM, treated in Hebei Cangzhou Central Hospital (Cangzhou, China) between 2011 and 2013 were enrolled in the present study. Patients underwent the following routine diagnostic investigations: Complete routine blood examination; categorization of leukocytes in the peripheral blood; bone marrow biopsy; immune fixation electrophoresis; immunoglobulin class determination and quantification; measurement of $\beta 2$-microglobulin, CRP and renal function; general skeletal $\mathrm{X}$-ray examination/emission computed tomography test; and chromosomal analysis.

Extramedullary infiltration was assessed using the hydrothorax centrifugal smear of myeloma cells, needle aspiration puncture, or during the period of follow-up in patients with tongue amyloidosis (one case), lung infiltration (four cases) or gingival infiltration (two cases). Patients with primary plasma cell leukemia were excluded.

Patients were treated as follows: 6 patients received MP (melphalan and prednisone) therapy, while 34 patients were treated with the M2 regimen (carmustine, cyclophosphamide, melphalan and prednisone), with the aim of controlling plasma cell proliferation. Seven patients were also treated with the VAD regimen (new catharanthus, adriamycin and dexamethasone) as the M2 regimen and MP were ineffective in these individuals. Patients were divided into two effective groups, remission (those exhibiting partial or complete remission) or stable disease and an ineffective group (those with progressive disease). In addition, 30 healthy volunteers (19 males, 11 females) with a mean age of 34 years (range, 22-53 years) were enrolled at Hebei Cangzhou Central Hospital as the healthy control group.

Flow cytometry. uPAR (CD87), CD56 and CD38 molecules on platelets from $1 \mathrm{ml}$ of bone marrow plasma cells, were measured using flow cytometry, which was performed with phycoerythrin (PE)-conjugated monoclonal mouse anti-human CD38 (\#555460), CD56 (\#556647) and uPAR (CD87-PE; \#555768) antibodies, and a fluorescein isothiocyanate (FITC)-conjugated monoclonal mouse anti-human CD38 (CD38-FITC; \#555459) antibody (all purchased from BD Biosciences, San Jose, CA, USA; dilution, 1:15). These monoclonal antibodies were detected in triple stainings, and all combinations of CD38, CD78 and CD56 were included, for the specific identification of plasma cells. Cell reactivity was analyzed using a Becton Dickinson FACSort, with CellQuest v3.1 software (BD Biosciences). At least 10,000 events were acquired for each monoclonal antibody combination. The relative fluorescence intensity was calculated as the mean fluorescence intensity (MFI) produced by a specific antibody, divided by the background MFI value generated by the control antibody for each patient sample. Irrelevant isotype-matched mouse antibodies (PE-Cy ${ }^{\mathrm{TM}} 5$ Mouse IgG1 $\kappa$ Isotype; \#555750; BD Biosciences) were used as negative controls.

ELISA. Peripheral venous blood $(2 \mathrm{ml}$, after the first $5 \mathrm{ml}$ was discarded) was drawn into blood collection tubes containing sodium citrate $(0.5 \mathrm{ml})$, gently mixed 3-5 times and centrifuged at $402 \mathrm{x} \mathrm{g}$ for $5 \mathrm{~min}$. The serum was collected and stored in the fridge at $-80^{\circ} \mathrm{C}$. Serum human suPAR concentrations were determined using quantitative human colorimetric ELISA kits (Bio-Rad Model 550, Quanti-kine HumanuPAR Immunoassay kit, USA), according to the manufacturer's instructions.

Statistical analysis. All data were analyzed using SPSS software version 18.0 (SPSS Inc., Chicago, IL, USA). Data are presented as mean \pm standard deviation, and $\mathrm{P}<0.05$ was considered to indicate a statistically significant difference. Comparisons of continuous variables were performed using a t-test for paired samples, while the $\chi^{2}$ test was used for the comparison of categorical variables. Patient survival was estimated using the Kaplan-Meier method, from the date of diagnosis until death from any cause or until survival for $>2$ years. Survival curves were compared statistically using the log-rank test. Proportional hazard regression analysis and logistic regression analysis were used to identify the most significant independent prognostic variables affecting patient survival.

\section{Results}

Association between suPAR expression level and treatment efficacy. uPAR was positive in the bone marrow in all 40 patients with MM ( $\geq 20 \%$ cells expressing uPAR was defined as positive). Typical morphological data from 1 patient are presented in Fig. 1, and clinical and laboratory data of all patients are presented in Table I. suPAR levels was measured in blood samples from 40 patients with 
A
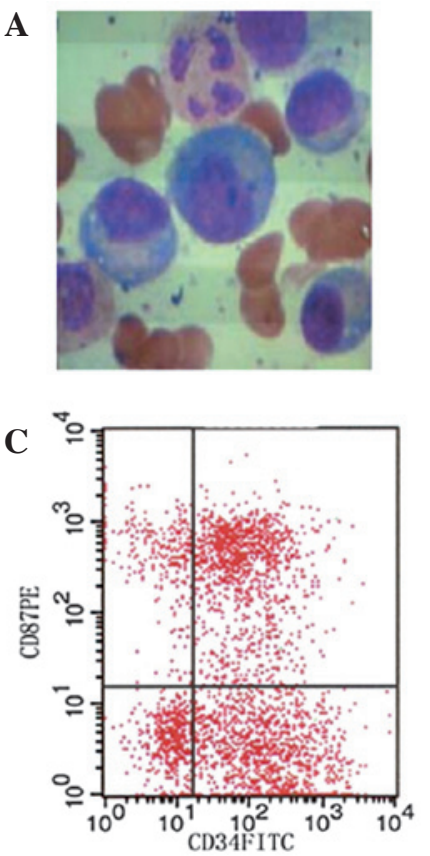

B
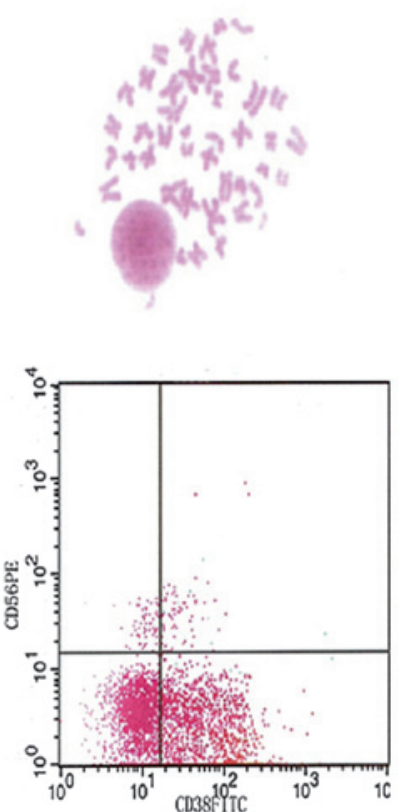

Figure 1. (A) Bone marrow morphology, (B) karyotype alternations and (C) immunophenotype of one MM patient (female; age, 56 years; IgG- $\lambda$ ). Bone marrow aspirate smears indicated that the percentage of plasma cells was $40.5 \%$; Karyotype: 46, XX, del 13q21. Immunophenotype: CD87, 40.85\%; CD56, (-); CD38,: 56.67\%; suPAR, 970.6 pg/ml. MM, multiple myeloma; suPAR, soluble urokinase plasminogen activator.

MM and 20 age-matched normal controls. suPAR levels in patients with MM were significantly higher than those of the controls: The mean suPAR level in the healthy control group was $233.47 \pm 85.22 \mathrm{pg} / \mathrm{ml}$ (range, $138.3-330.9 \mathrm{pg} / \mathrm{ml}$ ). Patients with $\mathrm{MM}$ were divided into two effective groups, remission (those exhibiting partial or complete remission) or stable disease and an ineffective group (those exhibiting progressive disease). The suPAR levels in the effective groups were $257.6 \pm 32.47$ and $331.0 \pm 99.80 \mathrm{pg} / \mathrm{ml}$, respectively, which was not significantly different compared with levels in the normal control group $(\mathrm{P}>0.05)$. By contrast, the suPAR level in the invalid group was $562.2 \pm 291.0 \mathrm{pg} / \mathrm{ml}$, which was significantly difference from that in the normal control group $(\mathrm{P}<0.01)$ and the effective groups $(\mathrm{P}<0.05$; Table II).

Differences in SUPAR expression levels prior to and following treatment. Seventeen patients completed follow-up for measurement of suPAR expression, from their first visit to the end of chemotherapy. The mean suPAR level at presentation was $537.65 \pm 131.43 \mathrm{pg} / \mathrm{ml}$. The 17 patients were treated with the M2 regimen or then VAD. Following chemotherapy, they were divided into an effective group (10 cases; suPAR, 298.76 $\pm 108.59 \mathrm{pg} / \mathrm{ml})$ and an ineffective group ( 7 cases; suPAR, $371.10 \pm 98.46 \mathrm{pg} / \mathrm{ml}$ ). The mean level of suPAR prior to treatment was higher than that following treatment in the effective group $(\mathrm{P}<0.01)$ and the ineffective $\operatorname{group}(\mathrm{P}<0.01$; Table III $)$.

Association between SUPAR expression level and disease severity. suPAR levels were positively correlated with disease stage $(\mathrm{P}<0.01)$, renal function $(\mathrm{P}<0.05), \mathrm{CRP}(\mathrm{P}<0.005)$,

Table I. Clinicopathological parameters of 40 patients with multiple myeloma.

Clinicopathological criteria

$\mathrm{n}$

Age (years)

$\leq 60$

$>60$

Gender

Female

Male

Disease stage

I-II

III

Renal dysfunction

Negative

Positive

Hemoglobin (g/dl)

$\leq 10$

$>10$

C-reactive protein $(\mathrm{mg} / \mathrm{l})$

$\leq 10$

$>10$

ß2-microglobulin ( $\mathrm{mg} / \mathrm{l})$

$\leq 4.0$

$>4.0$

Extramedullary involvement

Yes

No

$13 q 14$

Deleted

Normal

Treatment

MP (melphalan and prednisone)

M2 (carmustine, vincristine, cyclophosphamide,

$\beta 2$-microglobulin $(\mathrm{P}<0.001)$, extramedullary involvement $(\mathrm{P}<0.001)$, chromosome 13 deletion $(\mathrm{P}<0.01)$ and survival $<2$ years $(\mathrm{P}<0.01)$. No correlation was observed between hemoglobin expression and suPAR levels (Table IV).

Logistic regression was applied in order to analyze the correlation between survival time and clinicopathological criteria, including gender, age, disease stage, renal function, hemoglobin, CRP, $\beta 2$-microglobulin, deletion of chromosome 13, extramedullary invasion and suPAR expression (data not shown). The results indicated that disease stage and suPAR expression predicted a survival time of $<2$ years $(\mathrm{P}<0.01)$.

\section{Discussion}

uPA is a specific serine protein with a molecular weight of 5000 Mr, which catalyzes the conversion of plasminogen to plasmin in the extravascular space. Plasmin is a broad-spectrum 
Table II. Association between suPAR expression and treatment efficacy.

\begin{tabular}{lccc}
\hline Effect & $\begin{array}{c}\text { Patients, } \\
\mathrm{n}\end{array}$ & $\begin{array}{c}\text { suPAR, pg/ml } \\
(\text { mean } \pm \text { SD) }\end{array}$ & P-value \\
\hline Remission & 13 & $257.6 \pm 32.47$ & $\mathrm{NS}$ \\
Stable disease & 19 & $331.0 \pm 99.80$ & $\mathrm{NS}$ \\
Ineffective & 8 & $562.2 \pm 291.0^{\mathrm{b}}$ & $0.005<\mathrm{P}<0.01^{\mathrm{a}}$ \\
Control & 30 & $233.47 \pm 85.22$ & \\
\hline
\end{tabular}

Remission, stable disease and ineffective groups were compared with the control group, respectively. ${ }^{\mathrm{a}} \mathrm{t}=2.91 .{ }^{\mathrm{b}} \mathrm{P}<0.05 \mathrm{vs}$. control. $\mathrm{SD}$, standard deviation; NS, not significant $(\geq 0.05)$; suPAR, soluble urokinase plasminogen activator receptor.

Table III. Contrast of suPAR expression before and after treatment.

\begin{tabular}{lrcr}
\hline Group & n & $\begin{array}{c}\text { suPAR, pg/ml } \\
(\text { mean } \pm \text { SD) }\end{array}$ & P-value \\
\hline $\begin{array}{l}\text { Prior to treatment } \\
\text { Following treatment }\end{array}$ & 17 & $537.65 \pm 131.43^{\mathrm{a}}$ & $<0.01$ \\
$\quad$ Effective & 10 & $298.76 \pm 108.59$ & $>0.05$ \\
$\quad$ Ineffective & 7 & $391.10 \pm 98.46^{\mathrm{a}}$ & $<0.01$ \\
Control & 30 & $233.47 \pm 85.22$ & \\
\hline
\end{tabular}

All groups were compared with the control group, respectively. ${ }^{\mathrm{a}} \mathrm{P}<0.05$ vs. control. SD, standard deviation; suPAR, soluble urokinase plasminogen activator.

protein, which activates metalloproteinases, thereby stimulating tissue differentiation and growth, cell adhesion and migration in physiological and pathological conditions (7). During the catalytic process, uPA combines with its ligand, uPAR, also termed CD87, which is a member of the GPI-AP family. A recent study demonstrated that uPAR is a single-chain glycoprotein with high affinity for uPA and precursor-uPA (Kd10-9-10-12 grammole) (8). uPAR anchors to the cell membrane with c-terminal GPI. It predominantly mediates plasminogen activation, and is associated with cell migration, cell adhesion, tumor growth, metastasis and chemotactic responses.

Under physiological conditions, uPAR is present on the surface of a variety of types of cells, such as leukocytes, including neutrophils, monocytes, macrophages, acidophilic granulocyte and activated T lymphocytes; endothelial cells; and fibroblasts. UPAR is directly involved in the chemotaxis of neutrophils and monocytes, as a result of the change in structure of UPAR, which consists of three parts; D1, D2 and D3 $(9,10)$. uPA joins to the UPAR at its n-terminal, and the c-terminal joins with fibrinolytic enzymes on the cell membrane (11). A change in the conformation of UPAR reveals a sequence of chemokines in the D1 and D2 sections (7). Since uPAR may combine with the matrix protein and mediate the cell adhesion process, uPAR and UPA are able to regulate the adhesion of bone marrow cells and matrix proteins (12). It was hypothesized that UPAR may
Table IV. Correlations between suPAR and other variables.

\begin{tabular}{|c|c|c|c|}
\hline Variable & $\begin{array}{c}\text { suPAR, pg/ml } \\
(\text { mean } \pm \text { SD) }\end{array}$ & $t$ & P-value \\
\hline Stage & & 1.93 & $<0.05$ \\
\hline I-II & $325.4 \pm 91.79$ & & \\
\hline III & $465.0 \pm 231.58$ & & \\
\hline Renal dysfunction & & 2.45 & $<0.01$ \\
\hline Negative & $372.9 \pm 197.70$ & & \\
\hline Positive & $551.9 \pm 242.68$ & & \\
\hline Hemoglobin (g/dl) & & 0.933 & $>0.05$ \\
\hline$\leq 10$ & $449.0 \pm 273.31$ & & \\
\hline$>10$ & $378.0 \pm 169.79$ & & \\
\hline C-reactive protein (mg/l) & & 2.85 & $<0.005$ \\
\hline$\leq 10$ & $359.2 \pm 151.94$ & & \\
\hline$>10$ & $566.5 \pm 287.88$ & & \\
\hline$\beta 2$-microglobulin (mg/l) & & 3.50 & $<0.001$ \\
\hline$\leq 4.0$ & $332.34 \pm 92.90$ & & \\
\hline$>4.0$ & $554.1 \pm 285.09$ & & \\
\hline Extramedullary involvement & & 3.84 & $<0.001$ \\
\hline Yes & $570.5 \pm 311.08$ & & \\
\hline No & $372.5 \pm 175.65$ & & \\
\hline $13 q 14$ & & 2.67 & $<0.01$ \\
\hline Deleted & $570.54 \pm 311.08$ & & \\
\hline Normal & $372.53 \pm 158.97$ & & \\
\hline Survival time (years) & & 3.50 & $<0.01$ \\
\hline$\leq 2$ & $646.01 \pm 103.97$ & & \\
\hline$>2$ & $333.02 \pm 85.37$ & & \\
\hline
\end{tabular}

NS, not significant $(\geq 0.05)$; suPAR, soluble urokinase plasminogen activator; SD, standard deviation; t, t-statistic.

form a complex with integrins, such as CD11b, and that it could then mediate the interaction between UPAR and the cell scaffold, which may stimulate cell adhesion $(13,14)$. Furthermore, uPAR may also form a functional connection with $\beta 1, \beta 2$ or $\beta 3$ integrin, or with other proteins that have tyrosine kinase activity (15). A recent study reported that the movement of bone marrow into fibrin, caused by the proteolysis of plasmin, is activated by plasminogen on the surface of MM plasma cells (16).

It has previously been shown that UPA and UPAR are expressed on myeloma cells in patients with MM, which may lead to the activation of the protein hydrolysis system, and that this process may be associated with the degradation of the marrow stroma in MM (17). Flow cytometry analysis demonstrated that uPAR (CD87) expression was associated with the differentiation stage of myeloma cells in MM, and that CD45+ immature plasma cells exhibited high uPAR expression, as well as CD138 and CD56 (18). It has also been reported that CD138 and CD56 are involved in the process of cell adhesion (19). These studies have shown that uPAR may participate in the regulation of plasma cells, including CD56+ cells, and affect the proliferation of malignant plasma cells. A separate study demonstrated that plasma cells from patients with monoclonal 
$\gamma$ globulin disease also expressed uPAR. Therefore uPAR expression is not only a characteristic of MM cells, but also an indicator of clonal plasma cell proliferation (20).

The conventional hypothesis was that MM prognosis was associated with disease stage, renal function, anemia, CRP, $\beta 2$-microglobulin, abnormalities of chromosome 13 and extramedullary infiltration at presentation. Hjertner et al (21) measured uPA/uPAR expression in four strains of myeloma cells of untreated patients with MM, using immunocytochemistry staining and flow cytometry. The results showed that the MM tumor cells expressed UPA/uPAR and exhibited corresponding proteolytic activity, and that the uPA/uPAR levels were associated with the maturity of tumor cells. The authors hypothesized that uPAR expression may affect the invasiveness and osseous injury of myeloma cells. Rigolin et al (20) and Luo et al (22) also proposed that uPAR expression may be associated with extramedullary infiltration and a poor prognosis in patients with MM. Although all patients expressed uPAR on bone marrow cells in the present study, the expression of this molecule was not directly correlated with disease stage, renal function, hemoglobin, CRP, $\beta 2$-microglobulin, abnormalities of chromosome 13 or extramedullary infiltration.

Therefore, a connection between UPAR expression and clinical characteristics was required. This was hypothesized to be suPAR. suPAR is a uPAR variant lacking a GPI anchor, and exists in the bodily fluids or tumor tissue in soluble form. To date, it is unclear how suPAR is formed. As mononuclear cells and neutrophils exhibit uPAR expression, it was proposed that suPAR in healthy individuals may be derived from cell ageing, cell death, differentiation of the bone marrow, and the formation of megakaryocytes and platelets $(23,24)$. Previous studies have also demonstrated that the elevated suPAR levels, observed in patients with cancer, are associated with a poor outcome (25). Although suPAR is released by tumor cells, the speed of its secretion was not correlated with uPAR expression and the quantity of tumor cells (26). Other studies have demonstrated that uPAR expression in plasma cells is not associated with the suPAR levels in the peripheral blood $(11,27)$. No correlation was observed between hemoglobin and suPAR expression in the present study.

There has been much research into the expression of suPAR in solid tumors, including prostate cancer, ovarian cancer, cervical cancer, liver cancer and colorectal cancer (28-30). These studies all found that elevated suPAR expression was associated with a poor prognosis. However, there have been few studies that have investigated the expression of suPAR in blood cancers.

Luo et al (22) measured uPA and suPAR concentrations in 34 patients with MM, and observed the uPA/suPAR expression prior to and following chemotherapy in 6 patients with MM. The present study also demonstrated that suPAR levels in patients with MM were significantly higher than those of the control group. Furthermore, the level of suPAR in patients with advanced MM was significantly higher than the level in the control group or in the patients with stable $\mathrm{MM}(\mathrm{P}<0.01)$, while no significant difference was detected in suPAR levels between patients with MM and the control group ( $\mathrm{P}>0.05$; Table II). In the present study, 17 patients were followed up until the end of treatment. The mean suPAR level $(537.65 \pm 131.43 \mathrm{pg} / \mathrm{ml})$ prior to treatment was significantly higher than that of the control group (Table III). These 17 patients were treated with the $\mathrm{M} 2$ regimen and then VAD therapy where the M2 regiment had been ineffective. Following chemotherapy, patients were divided into an effective group (10 cases, suPAR level, $298.76 \pm 108.59 \mathrm{pg} / \mathrm{ml}$ ) and an invalid group (7 cases; suPAR level, $371.10 \pm 98.46 \mathrm{pg} / \mathrm{ml}$ ). There was a significant difference in suPAR levels between the effective group and the invalid group $(\mathrm{P}<0.05)$, while no significant difference was detected between the effective group and healthy controls. Following treatment, the suPAR level in all patients was lower than that prior to treatment, which may have been due to the reduction in plasma cells following chemotherapy. Therefore, suPAR expression may predict the stability of the disease and efficacy of the treatment.

In addition, the present study analyzed the association between suPAR expression, and disease stage, renal function, hemoglobin, CRP, $\beta 2$-microglobulin, chromosome 13 abnormalities and extramedullary infiltration. The results showed that suPAR expression in stage III disease was higher than that in stage I-II $(\mathrm{P}<0.05)$. suPAR expression in the group with abnormal renal function was higher than that in the group with normal renal function $(\mathrm{P}<0.01)$. The suPAR expression in patients with a hemoglobin $<10 \mathrm{~g} / \mathrm{dl}$ group was higher than that in the group with a hemoglobin $\geq 10 \mathrm{~g} / \mathrm{dl}$, although this was not statistically significant. suPAR expression in the group with CRP $>10 \mathrm{mg} / \mathrm{l}$ was higher than that in the group with a CRP $\leq 10 \mathrm{mg} / \mathrm{l}(\mathrm{P}<0.005)$. The suPAR expression in the group with a $\beta 2$-microglobulin of $>4.0 \mathrm{mg} / \mathrm{l}$ was significantly higher than that in the group with $\beta 2$-microglobulin $\leq 4.0 \mathrm{mg} / \mathrm{l}(\mathrm{P}<0.001)$. In addition, the suPAR expression in those with a deletion in chromosome 13 was significantly higher than that in those with a normal chromosome 13 or with other chromosomal abnormalities $(\mathrm{P}<0.01)$. Finally, there was a significant difference in suPAR levels between those with and without extramedullary infiltration $(\mathrm{P}<0.001)$. All 7 patients with extramedullary infiltration, either had marrow infiltration at the time of presentation or developed it $<1$ year following diagnosis. This indicated that high suPAR expression may be associated with early extramedullary infiltration. In conclusion, disease stage, renal function, CRP, $\beta 2$-microglobulin, deletion of chromosome 13 and extramedullary infiltration were positively correlated with suPAR expression, which further indicated that measuring the level of suPAR may help to predict prognosis and survival rates.

The mechanism underlying the effect of suPAR in MM remains unclear. It has been hypothesized that the suPAR and its components, D2 and D3, may compete with uPAR at the cell membrane, thus influencing the uPAR utilization. High expression of suPAR is associated with cell adhesion and extracellular matrix adhesion (20). This process may have two different underlying mechanisms. The first is competition with uPAR on the plasma membrane surface to bind to integrin. The second is a reduction in the utilization of uPAR by detachment of UPAR from the plasma membrane. High expression of suPAR may predict a reduction in the adhesion of plasma cells to the bone marrow stroma, facilitating spread outside the marrow, which leads to faster disease progress and shortened survival time (31).

The average survival time of patients with MM was 3 years in the present study. All 40 patients (17 of whom completed post-chemotherapy suPAR assessment) were 
followed up until mortality or survival at $\geq 2$ years in order to examine the association between the level of suPAR and patient survival. This analysis demonstrated that suPAR expression in patients who survived for $>2$ years (28 cases) was significantly lower than that in patients who survived for $<2$ years ( 12 cases). The results also showed that suPAR expression in patients surviving $<2$ years was significantly higher than that of the normal control group $(\mathrm{P}<0.01)$, which demonstrated that the high expression of suPAR was directly correlated with survival. Furthermore, the association between suPAR expression, and gender, age, disease stage, renal function, hemoglobin, CRP, $\beta 2$-microglobulin, deletion of chromosome 13 and extramedullary infiltration was analyzed, using logistic regression. The results indicated that disease stage and suPAR were independent factors, which predicted a survival time of $<2$ years.

Disease progression and marrow infiltration have previously been considered to be the major factors affecting prognosis in patients with MM. Early diagnosis, and early treatment and chemotherapy were key to improving prognosis, and to prolonging patient survival, prior to the development of rising plasma cell counts and infiltration. Currently, clinicians rely on bone marrow examination, $\mathrm{CRP}, \beta 2$-microglobulin and imaging in order to evaluate the curative effect and prognosis. However, these tests may be invasive, with poor specificity and a delay in acquiring imaging results. Studies have also indicated that CRP and $\beta 2$-microglobulin are correlated with clinical factors and disease stage, and may predict early mortality, although they were not found to predict treatment response, and were unrelated to suPAR expression (32). suPAR expression is correlated with survival in addition to treatment efficacy. Therefore it may be a novel predictor for use in conjunction with morphology and imaging.

In conclusion, the present study demonstrated that UPAR was positive in the bone marrow cells in all patients with MM. suPAR levels were positively correlated with disease stage, renal function, CRP, $\beta 2$-microglobulin, extramedullary involvement, chromosome deletion and survival time, while they were negatively correlated with hemoglobin concentration. The results indicated that disease stage and suPAR were independent factors, which predicted survival of $<2$ years. suPAR expression does not have a unified reference value, due to variations in testing methods and specimen preparation. However, a number of studies have confirmed that its expression is significantly higher in inflammatory states and cancer. The present study investigated the association between suPAR expression and MM, and demonstrated that high suPAR expression was associated with disease progression, shortened survival and early extramedullary infiltration. However, further investigation is required in order to fully ascertain its value in clinical practice.

\section{References}

1. Hjertner O, Qvigstad G, Hjorth-Hansen H, Seidel C, Woodliff J, Epstein J, Waage A, Sundan A and Börset M: Expression of urokinase plasminogen activator and the urokinase plasminogen activator receptor in myeloma cells. Br J Haematol 109: 815-822, 2000.

2. Tarui T, Mazar AP, Cines DB and Takada Y: Urokinase-type plasminogen activator receptor (CD87) is a ligand for integrins and mediates cell-cell interaction. J Biol Chem 276: 3983-3990, 2001.
3. Mekkawy AH, Pourgholami MH and Morris DL: Involvement of urokinase-type plasminogen activator system in cancer: An overview. Med Res Rev 34: 918-956, 2014.

4. DeClerck YA and Jones PA: Effect of ascorbic acid on the resistance of the extracellular matrix to hydrolysis by tumor cells. Cancer Res 40: 3228-3231, 1980.

5. Reuning U, Sperl S, Kopitz C, et al: Urokinase-type plasminogen activator (uPA) and its receptor (uPAR): Development of antagonists of $\mathrm{uPA} / \mathrm{uPAR}$ interaction and their effects in vitro and in vivo. Curr Pharm Des 9: 1529-1543, 2003.

6. Lanza F, Castoldi GL, Castagnari B, et al: Expression and functional role of urokinase-type plasminogen activator receptor in normal and acute leukemic cells. Br J Haematol 103: 110-123, 1998.

7. Wei Y, Yang X, Liu Q, et al: A role for caveolin and the urokinase receptor in integrinmediated adhesion and signaling. J Cell Biol 144: 1285-1294, 1999.

8. Kindzelskii AL, Amhad I, Keller D, et al: Pericellular proteolysis by leukocytes and tumor cells on substrates: Focal activation and the role of urokinase-type plasminogen activator. Histochem Cell Biol 121: 299-310, 2004.

9. Fazioli F, Resnati M, Sidenius N, et al: A urokinase-sensitive region of the human urokinase receptor is responsible for its chemotactic activity. EMBO J 16: 7279-7286, 1997.

10. Gyetko MR, Todd RF III, Wilkinson CC and Sitrin RG: The urokinase receptor is required for monocyte chemotaxis in vitro. J Clin Invest 93: 1380-1387, 1994.

11. Béné MC, Castoldi G, Knapp W, et al: CD87 (urokinase-type plasminogen activator receptor), function and pathology in hematological disorders: A review. Leukemia 18: 394-400, 2004.

12. Wei Y, Eble JA, Wang Z, Kreidberg JA and Chapman HA: Urokinase receptors promote betal integrin function through interactions with integrin alpha3beta1. Mol Biol Cell 12: 2975-2986, 2001.

13. Gyetko MR, Sitrin RG, Fuller JA, Todd RF III, Petty H and Standiford TJ: Function of the urokinase receptor (CD87) in neutrophil chemotaxis. J Leukoc Biol 58: 533-538, 1995.

14. Gyetko MR, Chen GH, McDonald RA, Goodman R, Huffnagle GB, Wilkinson CC, Fuller JA and Toews GB: Urokinase is required for the pulmonary inflammatory responseto Cryptococcus neoformans: A murine transgenic model. J Clin Invest 97: 1818-1826, 1996.

15. Wei Y, Lukashev M, Simon DI, Bodary SC, Rosenberg S, Doyle MV and Chapman HA: Regulation of integrin function by the urokinase receptor. Science 273: 1551-1555, 1996.

16. Daci E, Udagawa N, Martin TJ, Bouillon R and Carmeliet G: The role of the plasminogen system in bone resorption in vitro. J Bone Miner Res 14: 946-952, 1999.

17. Hjertner O, Qvigstad G, Hjorth-Hansen H, Seidel C, Woodliff J, Epstein J, Waage A, Sundan A and Börset M: Expression of urokinase plasminogen activator and the urokinase plasminogen activator receptor in myeloma cells. Br J Haematol 109: 815-822, 2000.

18. Kara IO, Sahin B, Paydas S and Cetiner S: Flow cytometric evaluation of bone marrow plasma cells using CD19, CD45, CD56, CD38, and CD138 and correlation with bone marrow infiltration ratio in multiple myeloma patients. Saudi Med J 25: 1587-1592, 2004.

19. Rawstron A, Barrans S, Blythe D, Davies F, English A, Pratt G, Child A, Morgan G and Jack A: Distribution of myeloma plasma cells in peripheral blood and bone marrow correlates with CD56 expression. Br J Haematol 104: 138-143, 1999.

20. Rigolin GM, Tieghi A, Ciccone M, Bragotti LZ, Cavazzini F, Della Porta M, Castagnari B, Carroccia R, Guerra G, Cuneo A, et al: Soluble urokinase-type plasminogen activator receptor (suPAR) as an independent factor predicting worse prognosis and extra-bone marrow involvement in multiple myeloma patients. Br J Haematol 120: 953-959, 2003.

21. Hjertner O, Qvigstad G, Hjorth-Hansen H, et al: Expression of urokinase plasminogen activator and the urokinase plasminogen activator receptor in myeloma cells. Br J Haematol 109: 815-822, 2000

22. Luo LH, Xu GB and Lu XG: Detection and clinical significance of plasma urokinase-type plasminogen activator and its soluble receptor in patients with multiple myeloma. Zhejiang Da Xue Xue Bao Yi Xue Ban 32: 529-532, 2003 (In Chinese).

23. Plesner T, Behrendt N and Ploug M: Structure, function and expression on blood and bone marrow cells of the urokinase-type plasminogen activator receptor, uPAR. Stem Cells 15: 398-408, 1997. 
24. Wohn KD, Kanse SM, Deutsch V, Schmidt T, Eldor A and Preissner KT: The urokinase-receptor (CD87) is expressed in cells of the megakaryoblastic lineage. Thromb Haemost 77: 540-547, 1997

25. Stephens RW, Nielsen HJ, Christensen IJ, Thorlacius-Ussing O, Sørensen S, Danø K and Brünner N: Plasma urokinase receptor levels in patients with colorectal cancer: Relationship to prognosis. J Natl Cancer Inst 91: 869-874, 1999.

26. Krüger A, Soeltl R, Lutz V, Wilhelm OG, Magdolen V, Rojo EE, Hantzopoulos PA, Graeff H, Gänsbacher B and Schmitt M: Reduction of breast carcinoma tumor growth and lung colonization by overexpression of the soluble urokinasetype plasminogen activator receptor (CD87). Cancer Gene Ther 7: 292-299, 2000.

27. Mustjoki S, Sidenius N, Sier CF, Blasi F, Elonen E, Alitalo R and Vaheri A: Soluble urokinase receptor levels correlate with number of circulating tumor cells in acute myeloid leukemia and decrease rapidly during chemotherapy. Cancer Res 60: 7126-7132, 2000.

28. Miyake H, Hara I, Yamanaka K, Arakawa S and Kamidono S: Elevation of urokinase-type plasminogen activator and its receptor densities as new predictors of disease progression and prognosis in men with prostate cancer. Int J Oncol 14: 535-541, 1999.
29. Riisbro R, Stephens RW, Brünner N, Christensen IJ, Nielsen HJ, Heilmann L and von Tempelhoff GF: Soluble urokinase plasminogen activator receptor in preoperatively obtained plasma from patients with gynecological cancer or benign gynecological diseases. Gynecol Oncol 82: 523-531, 2001.

30. Fernebro E, Madsen RR, Fernö M, Brünner N, Bendahl P, Christensen IJ, Johnson A and Nilbert M: Prognostic importance of the soluble plasminogen activator receptor, suPAR, in plasma from rectal cancer patients. Eur J Cancer 37: 486-491, 2001

31. Koolwijk P, Sidenius N, Peters E, Sier CF, Hanemaaijer R, Blasi F and van Hinsbergh VW: Proteolysis of the urokinase-type plasminogen activator receptor by metallopoteinase-12: Implication for angiogenesis in fibrin matrices. Blood 97: 3123-3131, 2001.

32. Greipp PR, Lust JA, O'Fallon WM, Katzmann JA, Witzig TE and Kyle RA: Plasmal cell labeling index and beta 2-microglobulin predict survival independent of thymidime kinase C-reactive protein in multiple myeloma. Blood 81: 3382-3387, 1993. 